Cadernos de Clio, Curitiba, n. ${ }^{\circ}$ 4, 2013

\title{
DO LADO DE CÁ DO RIO URUGUAI: PRÁTICAS NOMINATIVAS E INSERÇÃO SOCIAL DE INDÍGENAS EM RIO PARDO (RS, 1758-1765) ${ }^{1}$
}

Alysson de Ávila Costa ${ }^{2}$

Resumo: Este artigo estuda as práticas de nominação de índios oriundos das reduções jesuíticas dos Sete Povos das Missões, através de registros batismais da freguesia de Nossa Senhora do Rosário de Rio Pardo, no atual território do Rio Grande do Sul, entre 1758 e 1765. O levantamento sistemático das informações contidas em tais registros permitiu verificar certas peculiaridades dessa população na escolha dos nomes de seus batizandos, fazendo com que o resultado dessa pesquisa contrastasse com levantamentos semelhantes para outras populações da América portuguesa colonial. Parte-se disso para se pensar a relação entre portugueses, espanhóis e índios e suas práticas sociais, religiosas e culturais em meados do século XVIII.

Palavras-chave: Registros paroquiais, indígenas, onomástica, História do Brasil, História da América.

\section{Introdução}

O objetivo deste artigo é apresentar, analisar e discutir as práticas nominativas de indígenas oriundos dos Sete Povos das Missões em meados de 1750, tentando apreender como o nome escolhido no ato do batismo pode ser a porta de entrada para se pensar a inserção deste segmento social no mundo Ibero-americano.

${ }^{1}$ Esta pesquisa é fruto de uma bolsa de Iniciação Científica UFPR/TN.

${ }^{2}$ Aluno do $6^{\circ}$ período da graduação de História na Universidade Federal do Paraná (UFPR). A presente pesquisa é orientada pel Prof. ${ }^{a}$ Dr. ${ }^{a}$ Martha Hameister. Link para o lattes: http://lattes.cnpq.br/5593484122965018. 
Para isso, utilizou-se os registros paroquiais de batismo desta população: um livro de batismo exclusivo para indígenas, que abrange o período de 1758 a 1765 e que contem pelo menos 363 registros ${ }^{3}$. Com base nesta documentação foram feitos os seguintes procedimentos: a) levantouse de forma sistemática os nomes contidos nos registros; b) identificou-se os nomes mais frequentes para esta população para cada agrupados por sexo; c) quantificou-se os resultados e produziram-se quadros e representações gráficas para tais quantificações d) compararam-se os resultados obtidos com outros levantamentos e estudos já realizados e) da análise desses resultados específicos para a localidade e comparados às outras levantaram-se novas questões.

Para empreender uma análise da documentação e do levantamento realizado perpassaremos os seguintes temas: a) o contexto de formação das reduções jesuíticas dos Sete Povos das Missões; b) as querelas decorrentes das disputas territoriais entre portugueses e espanhóis que geraram, entre outros, acordos como o Tratado de Madri (1750), que tiveram um impacto direto sobre a região estudada; c) a produção da documentação paroquial decorrente dos ritos católicos praticados no contexto colonial, legislados pelas Constituições Primeiras do Arcebispado da Bahia (DA VIDE, 1707); d) e o estudo das práticas de nominação (onomástica) na literatura acadêmica.

Os resultados obtidos sugerem, além da necessidade de aprofundamento das questões levantadas pelo trabalho, uma relação entre as práticas

${ }^{3}$ Este número contabiliza o total de registros possíveis de serem levantados, levando em conta o estado de conservação da documentação, que se apresenta bastante danificada em algumas partes. 
Cadernos de Clio, Curitiba, n. ${ }^{\circ}$ 4, 2013

nominativas dos indígenas reduzidos e sua cristianização, levando em conta a influência jesuítica à qual estavam submetidos.

\section{Os Sete Povos das Missões}

Os Sete Povos das Missões foram reduções jesuítas fundadas entre 1682 e 1706 (ARAÚJO , 1986), que ocuparam o oeste do atual território do Rio Grande do Sul e abrigavam os índios Tape da região. Foram elas: Santo João, Santo Ângelo (ou Santo Anjo), São Borja, São Miguel, São Lourenço, São Nicolau e São Luis. Tais reduções faziam parte do método de colonização espanhol e integravam um conjunto maior de missões dos jesuítas, os Trinta Povos das Missões. A colonização dos povos indígenas fazia parte do projeto colonizador empreendido pelas coroas ibéricas, que tinham em seu cerne, também, um viés espiritual de catequizar e trazer para o seio da cristandade os povos a serem descobertos no Novo Mundo. Por este motivo, indígenas eram administrados ou congregados em reduções, onde recebiam os sacramentos católicos e assim reproduziam, pelo menos em parte, as práticas religiosas dos colonizados ibéricos.

Estas reduções estavam inseridas em um quadro político e territorial mais amplo e complexo, que inclui a Bacia do Prata, na qual se situava a Colônia de Sacramento. Teoricamente em território espanhol, às margens do Rio da Prata, foi fundada em 1680 pelo português Manuel Lobo, então governador da Capitania do Rio de Janeiro. Começava um longo período de disputas territoriais, no campo de batalha e no campo diplomático. Acompanhamos em Araújo (2004) os seguidos cercos espanhóis a Sacramento - cercos estes que resultavam na queda do forte em mãos espanho- 
Cadernos de Clio, Curitiba, n. ${ }^{\circ}$ 4, 2013

las, mas que pelo jogo político entre os reis ibéricos retornavam aos portugueses.

Para dar fim a décadas (1680-1750) de contendas e beligerância em torno de Sacramento, as coroas ibéricas assinam em 1750 o Tratado de Madri, que propõe uma nova divisão territorial entre Espanha e Portugal na América, próxima aos atuais contornos do país. Além de acordarem o uti possidetis, premissa pela qual cada uma das coroas ficariam com o território já ocupado - dando larga vantagem à Portugal, que avançava indevidamente por uma vasta extensão territorial (ARAÚJO, 1986) -, estabeleceram a permuta entre a Colônia de Sacramente e a região das missões jesuíticas à margem esquerda do Rio Uruguai: a primeira passaria definitivamente aos espanhóis, enquanto a segunda se tornaria território português.

A fim de por em prática o acordo, que modificaria a fronteira oeste do território luso, destacamentos espanhóis (comandados por Francisco Graell) e portugueses (sob comando de Gomes Freire de Andrada) marcharam, a partir de 1754, para a região missioneira, para demarcarem o sul da divisão territorial do tratado. Encontraram a resistência de jesuítas e indígenas, que não aceitavam nem o domínio português ${ }^{4}$, nem a saída da região. O resultado da resistência ficou conhecida na historiografia como “Guerra Guaranítica” (GOLIN, 1998), na qual padeceram centenas de índios entre 1754 e 1758, além de portugueses e espanhóis.

\footnotetext{
${ }^{4}$ Vale lembrar que as gerações anteriores dos índios reduzidos em 1750 já tinham guerreado com as bandeiras paulistas e foram obrigados a deixar este território por volta de 1630, tornando a ocupa-lo novamente 50 anos depois.
} 
Cadernos de Clio, Curitiba, n. ${ }^{\circ}$ 4, 2013

\section{Registros paroquiais}

É neste contexto que tem início em 1758 os registros batismais de indígenas das reduções jesuíticas espanholas, agora em território e sob jurisdição portuguesa, na freguesia de Nossa Senhora do Rosário de Rio Pardo. Os registros vem atender o imposto pelas Constituições Primeiras do Arcebispado da Bahia, documento publicado em 1707 por Sebastião Da Vide, para regulamentar a vida religiosa na América portuguesa. Os registros batismais seriam feitos segundo ordena tal documento:

Aos tantos de tal mês, e de tal ano batizei, ou batizou de minha licença o Padre N. nesta, ou em tal Igreja, a N. filho de N. e sua mulher N. e lhe pus os Santos Óleos: foram padrinhos N. e N. casados, viúvos, ou solteiros, fregueses de tal Igreja, e moradores em tal parte (DA VIDE, 1707, Título XX, § 71)

Temos, portanto, um conjunto de informações básicas nos registros batismais, entre eles a data do evento, os nomes dos envolvidos na cerimônia (batizando, pais e padrinhos), suas origens e situação matrimonial. É comum, porém, que as informações contidas em cada registro variem em quantidade e qualidade tendo em vista fatores difíceis de mensurar, mas entre eles vigoram a posição social dos agentes envolvidos.

De modo geral, esse tipo de documentação é largamente utilizado por alguns pesquisadores brasileiros, como João Fragoso (UFRJ), Sérgio Nadalin (UFPR), Ana Silvia Scott (UNISINOS) e Martha Hameister (UFPR). Para citar trabalhos recentes em nível de graduação e pós-graduação em História poderíamos citar a recente monografia de Nathan Camilo (UNISINOS, 2011) e o mestrado de Rachel Marques (mestrado, UFPR,

${ }^{5}$ Ortografia atualizada. 
2011). Faz-se ainda alusão à tradição historiográfica francesa da qual descendem os estudos e pesquisadores citados, dando destaque a publicação de Dupâquier (1984).

Para Fragoso (2004) a documentação gerada pelos ritos da fé católica é hoje um dos principais, se não um dos únicos documentos para a história social para alguns lugares e períodos do Rio de Janeiro setecentista. Podemos sugerir a mesma assertiva para algumas populações do Brasil colonial, como os indígenas presentes nos registros paroquiais estudados, entendendo estes registros como uma fonte em potencial para dizer da vida e da morte dessas pessoas. É isso que faz, por exemplo, Nadalin em “História e demografia: elementos para um diálogo” (2004), partindo majoritariamente da documentação paroquial de batismo, casamento e óbito, para acompanhar a vida de um casal da freguesia de Nossa Senhora da Luz de Curitiba entre 1772 e 1844.

Para a sociedade colonial do século XVIII o nome é importante, é elemento de inserção e aproximação: o nome cristão recebido no ato do batismo insere o inocente não só à comunidade espiritual da fé católica, como também na comunidade material e familiar que o cerca; além disso, o nome pode ser um patrimônio familiar que deve ser preservado, transmitido e perpetuado (HAMEISTER, 2008), dando ao nome um valor imaterial intrínseco.

Sendo assim, tendo em vista a importância do nome na comunidade luso-americana e suas possibilidades para a pesquisa histórica é que se propõe um estudo no qual ele é o principal objeto. Partindo das premissas de que o nome é escolhido e não imposto e que este nome carrega em si algum significado, tentaremos apreender o que as práticas nominativas 
dos indígenas de Rio Pardo, outrora das missões jesuíticas, revelam acerca da inserção dessa população na sociedade que a cerca.

\section{Apresentação dos resultados}

Foram levantados 363 registros, sendo 136 registros para batizandos do sexo masculino, 142 do sexo feminino e 85 registros cujo sexo e nomes não foram possíveis de se apreender na documentação, tendo em vista seu estado físico. Este levantamento gerou uma lista de 280 nomes 137 masculinos e 143 femininos ${ }^{6}$ - dispostos nos quadros a seguir.

Quadro 1: Nomes masculinos por ordem alfabética e suas respectivas frequên-

\begin{tabular}{|c|c|c|c|c|c|}
\hline Nome & Frequência & Nome & Frequência & Nome & Frequência \\
\hline Agostinho & 3 & Euzebio & 1 & Martinho & 1 \\
\hline Alexandre & 2 & Faustino & 1 & Miguel & 18 \\
\hline Anacleto & 2 & Francisco & 10 & $\begin{array}{c}\text { Miguel } \\
\text { Ariunde }\end{array}$ & 1 \\
\hline Anastácio & 1 & Gabriel & 1 & Nicolau & 3 \\
\hline André & 1 & Jeronimo & 1 & Panthaleão & 1 \\
\hline Antônio & 12 & Ignácio & 14 & Patrício & 1 \\
\hline Bernardino & 2 & Ignácio & & & \\
\hline Carlos & 2 & Inocencior & 1 & Pedro & 7 \\
\hline Chrisanto & 3 & Jacinto & 1 & Phelipe & 3 \\
\hline Christovão & 5 & Joaquim & 1 & Raphael & 1 \\
\hline Diogo & 3 & João & 9 & Santiago & 2 \\
\hline Dionizio & 1 & Jozé & 4 & Sebastião & 1 \\
\hline Domingos & 2 & Lázaro & 1 & Simão & 1 \\
\hline Donato & 1 & Leonardo & 2 & Teixeira & 1 \\
\hline
\end{tabular}

${ }^{6}$ Existem dois registros de gêmeos, ou seja, dois batizandos em um único registro, o que gera a diferença de 2 entre a quantidade de nomes e a quantidade de registros. 
Cadernos de Clio, Curitiba, n. ${ }^{\circ}$ 4, 2013

\begin{tabular}{|c|c|c|c|c|c|} 
Eugenio & 1 & Lourenço & 1 & Thomaz & 1 \\
\hline Eustaquio & 1 & Luiz & 2 & Timóteo & 1 \\
\hline
\end{tabular}

Fonte: $2^{\circ}$ livro de batismos de Rio Pardo (1758-1765). Disponível em:

www.familysearch.org

Quadro 2: Nomes femininos por ordem alfabética e suas respectivas frequências

\begin{tabular}{|c|c|c|c|c|c|}
\hline Nome & Frequência & Nome & Frequência & Nome & Frequência \\
\hline Agostinha & 3 & Clara & 1 & $\begin{array}{c}\text { Maria Pas- } \\
\text { choela }\end{array}$ & 3 \\
\hline Anastácia & 2 & Donata & 1 & Maria Roza & 4 \\
\hline Ângela & 1 & Dorothea & 1 & Martha & 1 \\
\hline Angelica & 1 & Ignácia & 7 & Martinha & 1 \\
\hline Anna & 6 & Izabel & 2 & Michaela & 2 \\
\hline Anna Maria & 1 & Jacobe & 1 & Petronilla & 1 \\
\hline Antônia & 4 & Joanna & 2 & Plácida & 1 \\
\hline Apolônia & 1 & Juliana & 3 & Quitéria & 1 \\
\hline Bárbara & 2 & Liberata & 1 & Roza & 1 \\
\hline Basilissa & 1 & Lizarda & 1 & Salomé & 1 \\
\hline Belchiora & 1 & Lourença & 2 & Simphoroza & 1 \\
\hline Bernardina & 2 & Lucresia & 1 & Thereza & 2 \\
\hline Bibiana & 1 & Magdalena & 4 & Úrsula & 1 \\
\hline Catharina & 3 & Maria & 59 & Vitória & 2 \\
\hline Cecilia & 2 & $\begin{array}{c}\text { Maria Cleo- } \\
\text { phas }\end{array}$ & 1 & & \\
\hline Celestina & 1 & $\begin{array}{c}\text { Maria Mag- } \\
\text { dalena }\end{array}$ & 2 & & \\
\hline
\end{tabular}

Fonte: $2^{\circ}$ livro de batismos de Rio Pardo (1758-1765). Disponível em: www.familysearch.org

Esses dois quadros contém todos os nomes levantados e as respectivas frequências em que aparecem, incluindo nomes compostos como Ignácio Xavier e Maria Magdalena, que serão agrupados daqui para frente pelo primeiro nome (prenome) para fins estatísticos. Um rol dos nomes mais escolhidos ficaria, então, como mostra o quadro a seguir. 
Cadernos de Clio, Curitiba, n. ${ }^{\circ}$ 4, 2013

Quadro 3: Os cinco nomes mais escolhidos para cada sexo.

\begin{tabular}{|c|c|c|c|}
\hline Nomes masculinos & Frequência & Nomes femininos & Frequência \\
\hline Miguel & 19 & Maria & 69 \\
\hline Ignácio & 15 & Anna & 7 \\
\hline Antônio & 12 & Ignácia & 7 \\
\hline Francisco & 10 & Antônia & 4 \\
\hline João & 9 & Magdalena & 4 \\
\hline
\end{tabular}

Fonte: $2^{\circ}$ livro de batismos de Rio Pardo (1758-1765). Disponível em: www.familysearch.org

O quadro acima mostra a frequência absoluta dos cinco nomes mais escolhidos para cada sexo. Para a população masculina de batizando temos, em ordem decrescente, Miguel, Ignácio, Antônio, Francisco e João, com 19, 15, 12, 10 e 9 registros cada um, respectivamente; para a população feminina temos Maria, Anna, Ignácia, Antônia e Magdalena, com 69, 7, 7, 4 e 4 registros cada uma, respectivamente. Abaixo, as ilustrações mostram as frequências relativas, dentro de todo conjunto de nomes.

A ilustração 1 mostra que o nome Miguel, presente em 19 registros, representa $14 \%$ das escolhas para o sexo masculino; Ignácio, presente em 15 registros, 11\%; Antônio, 9\%; Francisco, 7\%; João 7\%; e os demais nomes, que não estão entre os cinco mais escolhidos, representam pouco mais da metade das escolhas, 52\%. A ilustração 24 mostra que Maria, presente em 69 registros, representa 48\% das escolhas na pia batismal para o sexo feminino; Ignácia e Anna, presentes em 7 registros cada, representam, cada um, 5\%; Antônia e Magdalena, com 4 registros cada, representam 3\% das escolhas cada um; por fim, os demais nomes representam 36\% das escolhas para o sexo feminino. 
Cadernos de Clio, Curitiba, n. ${ }^{\circ}$ 4, 2013

Ilustração 1: A proporção dos cinco nomes masculinos mais escolhidos.

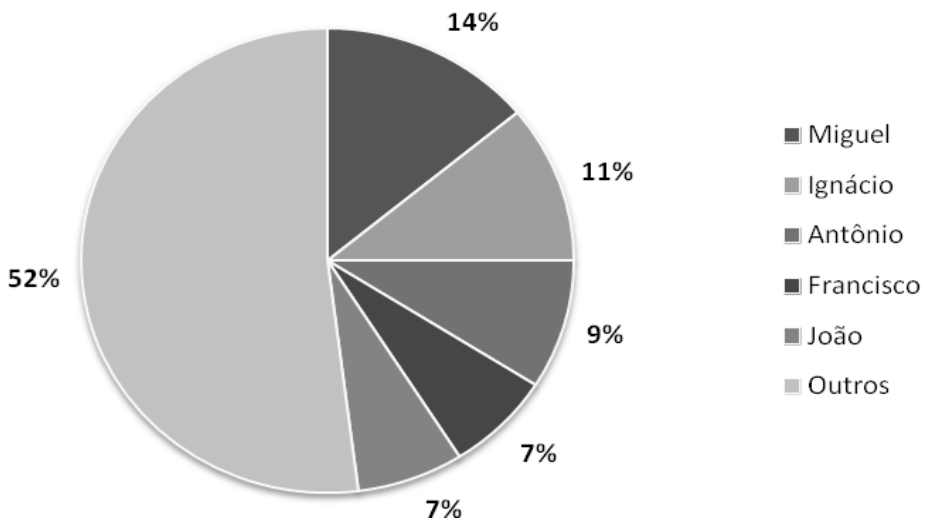

Fonte: $2^{\circ}$ livro de batismos de Rio Pardo (1758-1765). Disponível em:

www.familysearch.org

Ilustração 2: A proporção dos cinco nomes femininos mais escolhidos.

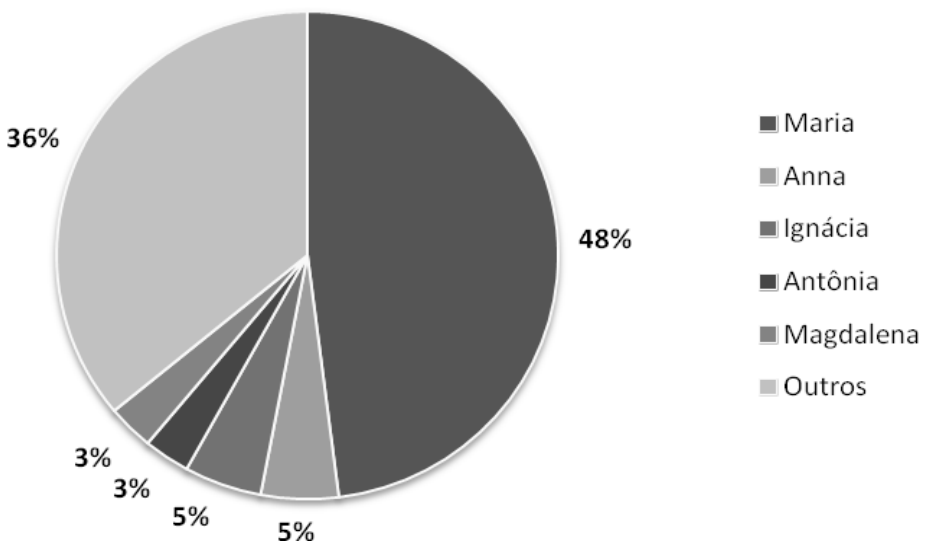

Fonte: $2^{\circ}$ livro de batismos de Rio Pardo (1758-1765). Disponível em:

www.familysearch.org 
Cadernos de Clio, Curitiba, n. ${ }^{\circ}$ 4, 2013

\section{Entre generalizações e peculiaridades}

Os estudos dos nomes, ou onomástica, para os domínios portugueses revelam algumas especificidades: primeiro, que o leque de nomes para serem dados era bastante reduzido; outra característica é a grande quantidade de homônimos na sociedade luso-americana. Essas duas informações são apresentadas tanto por Nadalin (2004), como por Hameister (2006; 2008). Não cabe discutir se um decorre do outro ou vice-versa, mas verificamos neste estudo essas duas características. A grande quantidade de homônimos é evidenciada pela grande repetição de Maria como escolha para o sexo feminino, congregando $48 \%$ da população feminina. Além disso, 64\% dos nomes femininos são distribuídos entre os cinco nomes mais escolhidos, evidenciando, também, a repetição de escolhas. Para o caso dos nomes masculinos, o mesmo fenômeno é observado, com alguma diferença em relação aos nomes femininos: os cinco nomes mais escolhidos somam $48 \%$ do total de nomes escolhidos.

Um levantamento bibliográfico dentre os pesquisadores que trabalham com o nome pôde fornecer algumas listas dos nomes mais escolhidos para outros lugares e tempos da América portuguesa. Nadalin (2004) apresenta um rol dos nomes mais comuns para meninos e meninas em Curitiba no século XVIII. Também o fazem Scott e Camilo (2011) para Porto Alegre e, mais recentemente, Marques (2011) para Rio Grande. Os resultados obtidos por estes pesquisadores podem ser sintetizados na tabela abaixo. 
Cadernos de Clio, Curitiba, n. ${ }^{\circ}$ 4, 2013

Quadro 4: Os cinco nomes mais escolhidos para cada sexo em outros locais da América portuguesa.

\begin{tabular}{|c|c|c|c|c|c|}
\hline \multicolumn{2}{|c|}{ Curitiba, século XVIII. } & \multicolumn{2}{|c|}{$\begin{array}{l}\text { Porto Alegre. } 1772 \text { - } \\
1810 .\end{array}$} & \multicolumn{2}{|c|}{ Rio Grande, 1750 - 1755.} \\
\hline $\begin{array}{c}\text { Nomes } \\
\text { masculinos }\end{array}$ & $\begin{array}{c}\text { Nomes } \\
\text { femininos }\end{array}$ & $\begin{array}{c}\text { Nomes } \\
\text { masculinos }\end{array}$ & $\begin{array}{c}\text { Nomes } \\
\text { femininos }\end{array}$ & $\begin{array}{c}\text { Nomes } \\
\text { masculinos }\end{array}$ & $\begin{array}{c}\text { Nomes } \\
\text { femininos }\end{array}$ \\
\hline Manoel & Maria & José & Maria & José & Maria \\
\hline Francisco & Anna & Manoel & Anna & Manoel & Anna \\
\hline José & Francisca & Antônio & Joaquina & Antônio & Rosa \\
\hline Antônio & Izabel & João & Francisca & João & Antônia \\
\hline João & Gertrudes & Francisco & Rita & Francisco & Francisca \\
\hline \multicolumn{2}{|c|}{ Fonte: Nadalin (2004) } & \multicolumn{2}{|c|}{$\begin{array}{l}\text { Fonte: Scott \& Camillo } \\
\text { (2011) }\end{array}$} & \multicolumn{2}{|c|}{ Fonte: Marques (2011) } \\
\hline
\end{tabular}

Os resultados apresentados anteriormente sobre os nomes mais escolhidos pela população indígena estudada mostram alguma variação em comparação com os apresentados pela bibliografia sobre o tema. Os nomes masculinos apresentam uma variação significativa, já que pelos dados levantados por este estudo Miguel e Ignácio são os dois nomes mais escolhidos, em desacordo com todos os outros estudos apresentados logo acima: no estudo de Nadalin (2004) são Manoel e Francisco; para Scott (2011), José e Manuel; e para Marques (2011) também José e Manoel. Contudo, Antônio, Francisco e João, que neste estudo ocupam da terceira a quinta colocação entre os nomes mais escolhidos, também aparecem em posições de destaque em outros levantamentos, sendo este um ponto de aproximação, enquanto o anterior mostra uma clara divergência.

No caso dos nomes femininos, a comparação com outros estudos mostra resultados muito semelhantes e muito diferentes ao mesmo tempo. Os resultados desta pesquisa estão em concordância com os apresentados 
por todos os outros estudos mencionados, onde Maria e Ana são os nomes mais escolhidos para as meninas. Contudo o levantamento feito na documentação de Rio Pardo mostra peculiaridades: dividindo a segunda posição com Ana, temos Ignácia, cujo correspondente masculino também é o segundo nome mais escolhido para a população masculina, e que não ocupa posição de destaque em nenhum outro estudo; e dividindo a quarta e quinta posição temos Antônia, que também não recebe destaque em outros estudos, somente no de Marques (2011), onde ocupa a quarta posição, e Magdalena - nome raramente visto em registros batismais, figura nesta documentação como um dos nomes mais escolhidos.

É importante lembrar que Ignácio (ou Inácio) é um nome muito significativo para a Ordem Jesuíta, pois é este o nome do fundador e importante líder da ordem: Inácio de Loyola, que fundou a Ordem no século XVI (MULLET, 1984). É notável que tanto as versões masculina e feminina do nome são encontradas entre as mais escolhidas, ao passo que os outros estudos apresentados não os identificam como um nome muito recorrente. É importante destacar que estes outros estudos mencionados trabalham com a América portuguesa no século XVIII, e que quase nenhuma comunidade, vila ou freguesia estudada tinha contato intenso com jesuítas, ou seja, justamente o oposto do que acontecia com os indígenas das reduções espanholas, reduções estas que foram fundadas e mantidas por jesuítas.

\section{Conclusões}

Ressalta-se o papel ativo da população indígena dos Sete Povos das Missões em se fazer presente na documentação paroquial de Rio Pardo a 
partir de 1758, momento subsequente à Guerra Guaranítica, na qual o território missioneiro passou a ser português sem, contudo, dar fim à questão territorial entre portugueses e espanhóis. Dentre as opções dos indígenas estavam a permanência no território, o retorno para a margem direita do Rio Uruguai, como já acontecera no século XVII com seus antepassados, ou perder-se nos matos da região. Temos, assim, acesso apenas a uma (provavelmente pequena) parcela dos índios reduzidos pelos jesuítas: a que permaneceu. Mas o que as práticas nominativas revelam é significativo: a adoção e reprodução das práticas católicas desenvolvidas quando sob tutela jesuítica, a adoção de prenomes dentro de um rol comum aos colonizadores ibéricos e mais especificamente adoção de prenomes que sugerem uma grande influência da tutela jesuítica exercida sobre essas populações indígenas.

Mas ao mesmo tempo que sugerimos a ação desses atores sociais em inserir-se na comunidade luso-americana, eminentemente católica, que os cercavam, podemos levantar problemas. Ao meu ver, um dos mais fortes é refletir sobre o grau de coerção e violência em que esse processo de inserção se deu. Devemos tratar, portanto, nem de não vitimizar a população nativa, nem de idealizar um frutífero contato entre autóctones e colonizadores. Não que o contato não tenha sido profícuo em termos políticos, militares e sociais, para indígenas e portugueses ou espanhóis, mas há um tanto de complexidade nessas relações entre os diversos agentes sociais do Brasil meridional setecentista que não couberam neste estudo. 
Cadernos de Clio, Curitiba, n. ${ }^{\circ}$ 4, 2013

\section{Bibliografia}

ARAÚJO, Rubens Vidal. Os jesuítas dos 7 Povos. Porto Alegre: Ed. Vozes, 1986.

CAMILO, Nathan. "Feliz o homem que deixa um bom nome": práticas de nomeação e apadrinhamento na freguesia de Nossa Senhora da Madre de Deus de Porte Alegre (1772-1810), São Leopoldo: UNISINOS, 2011 (monografia).

DA VIDE, Sebastião Monteiro. Constituições Primeiras do Arcebispado da Bahia. Coimbra: Colégio das Artes da Companhia de Jesus, 1707.

DUPÂQUIER, Jacques et al. (orgs.). Le prénom, mode et histoire. Les entretiens de Malher 1980. Paris : Éditions de l’École des Hautes Études en Sciences Sociales, 1984.

FRAGOSO, João. Efigênia Angola, Francisca Muniz forra parda, seus parceiros e senhores: freguesias rurais do Rio de Janeiro, século XVIII. Uma contribuição metodológica para a história colonial. In: Revista Topoi, v. 11, n. 21, jul.-dez. 2010, p. 74-106.

GOLIN, Tau. A guerra guaranítica. Porto Alegre: Editora da Universidade; Passo Fundo: UPF Editora, 1998.

HAMEISTER, Martha. Para dar calor à nova povoação: estratégias sociais e familiares na formação da Vila do Rio Grande através dos Registros Batismais (c.1738-c.1763). Rio de Janeiro: UFPR, 2006 (tese de doutorado).

. Uma contribuição ao estudo da onomástica no período colonial: os nomes e o povoamento do Extremo Sul da Colônia (Continente do Rio Grande de São Pedro, c. 1735-c.1777). In:DORÉ, Andréa; SANTOS, Antonio Cesar (Org). Temas setecentistas: governos e populações no Império Português. Curitiba: UFPR-SCHLA/Fundação Araucária, 2008.

MARQUES, Rachel. Por cima da carne seca: hierarquia e estratégias sociais no Rio Grande do Sul (c. 1750-1820). Curitiba: UFPR, 2011 (dissertação de mestrado).

MULLET, Michael. A contra-reforma. Lisboa: Gradiva, 1984.

NADALIN, Sérgio. História e demografia: elementos para um diálogo. Campinas: ABEP, 2004.

SCOTT, Ana Sílvia Volpi \& CAMILO, Nathan. "Todos os Nomes Das práticas de nomeação lusobrasileiras". In: V Jornada de Estudos Genealógicos: genealogia luso-brasileira. Porto Alegre: Arquivo da Cúria Metropolitana de Porto Alegre/Instituto Histórico e Geográfico do Rio Grande do Sul, 2011. (comunicação). 